Profesor dr Milojko Jevtović,
dipl. inž.
Institut Jugoslovenske inženjerske
akademije,
Beograd

\section{PARALELNO UMREŽAVANJE RAČUNARA}

UDC: 004.725 .5

Rezime:

U radu je izložena originalna koncepcija tehničkog rešenja paralelnog umrežavanja računara, kao i lokalnih računarskih mreža (LAN - Local Area Network), odnosno povezivanje $i$ istovremena komunikacija preko više različitih transportnih telekomunikacionih mreža. Opisano je jedno rešenje paralelnog umrežavanja, kojim je omogućen pouzdani prenos multimedijalnog saobraćaja i prenos podataka u realnom vremenu između računara ili LAN, istovremeno preko $N(N=1,2,3,4, \ldots)$ različitih, međusobno nezavisnih mreža širokog prostranstva (WAN - Wide Area Network). Paralelno umrežavanje zasnovano je na korišćenju univerzalnog modema, čije je rešenje, takođe, ukratko predstavljeno.

Ključne reči: računari, umrežavanje računara, računarske mreže, destrukcija mreža, funkcionalna otpornost mreža, univerzalni modem, paralelno umrežavanje.

\title{
PARALLEL NETWORKING OF THE COMPUTERS
}

\section{Summary:}

In this paper, new concept for paralel networking og the computers or LANs over diferent WAN telecommunications networks, is presented. One solution of the parallel networks, which enables reliable transfer of multimedial traffic and data transmission in real time between a computer of LAN via $N(N=1,2,3,4, \ldots)$ different inter-connected Wide Area Network. Connectons between computers or LANs and wide area networks are realiyed using universal modems whose solution has also been presented.

Key words: computer, computer networking, computer networks, network destruction, network survivability, universal modem, parallel networking.

\section{Uvod}

WAN računarske mreže mogu da budu izložene različitim oblicima ugrožavanja [1], među kojima su najteže destrukcije izazvane ratnim borbenim dejstvima (bombardovanjem) ili prirodnim nepogodama (zemljotresi, poplave, požari), koje mogu da zahvate velika prostranstva. Različite vrste mreža (bežične pokretne radio-mreže, satelitske mreže, žične mreže, optičke mreže) nisu jednako osetljive na ove vrste destrukcija, mada svaka od njih pojedinačno može da bude ugrožena destrukcijama određenog tipa.

Nameće se pitanje da li je realno moguće obezbediti zaštitu WAN mreža, odnosno funkcionalnu otpornost neke računarske mreže ako je ona izložena destruktivnim dejstvima. U radu je opisano rešenje koje se zasniva na paralelnom umrežavanju računara (ili LAN-ova), odnosno njihovom istovremenom povezivanju na više različitih tipova telekomunikacionih mreža, čime se obezbeđuje sigurna zaštita računarske mreže. To reše- 
nje provereno je u realnim uslovima funkcionisanja jedne računarske mreže, koja je bombardovanjem bila izložena velikim destrukcijama.

Pod paralelnim umrežavanjem računara podrazumeva se povezivanje računara preko jednog univerzalnog modema [2] sa više različitih interfejsa, preko kojih se modulisani signali istovremeno upućuju na $\mathrm{N}$ fizički i prostorno potpuno odvojenih transportnih telekomunikacionih WAN mreža. Na taj način omogućava se da signali preneti preko $\mathrm{N}$ različitih mreža budu sigurno prihvaćeni (sa neke od $\mathrm{N}$ mreža) od prijemnog modema, bez obzira na moguće destrukcije nekih od $\mathrm{N}$ mreža. Prijemni modem analizira signale koji su prispeli sa svih mreža i selektuje onaj signal koji obezbeđuje zahtevani kvalitet usluga (QoS - Quality of Service) [3]. Radi se o korisničkom QoS-u, kojim se definišu zahtevi za osnovne parametre kvaliteta, a to su: kašnjenje, varijacija kašnjenja i verovatnoća gubitka informacija. Na ovaj način moguće je realizovati funkcionalno otporne zaštićene računarske mreže, odnosno sigurnu komunikaciju između umreženih računara, bez obzira na destruktivna dejstva.

\section{Funkcionalna otpornost računarskih mreža}

Funkcionalna otpornost mreže (Network Survivability) predstavlja jednu od najznačajnijih osobina današnjih telekomunikacionih mreža. Ona može da se definiše kao mogućnost mreže da održi zahtevani nivo kvaliteta komunikacione usluge prilikom otkaza u mreži, odnosno otkaza nekih njenih linkova ili čvorova. Višeslojna funkcionalna otpornost mreže (Multilayer Network Survivability) odnosi se na mogućnost da se procedure ili šeme za postizanje funkcionalne otpornosti mreže smeste (ugnjezde) između dodirnih slojeva mreže, kao i na načine interakcije ovih šema.

Načini projektovanja funkcionalno otpornih računarskih mreža prikazani su na slici 1 . U projektovanju funkcionalno otpornih paketskih IP (Internet Protocol) računarskih mreža, koje na mrežnom sloju koriste MPLS (Multi Protocol Label Svitching) ili GMPLS (General MPLS) protokol, razlikuju se tri pristupa:

- funkcionalna otpornost „, $\mathrm{kraja}$ na kraj veze" - postoji samo jedan jednoslojni mehanizam koji obezbeđuje ovu funkcionalnu otpornost;

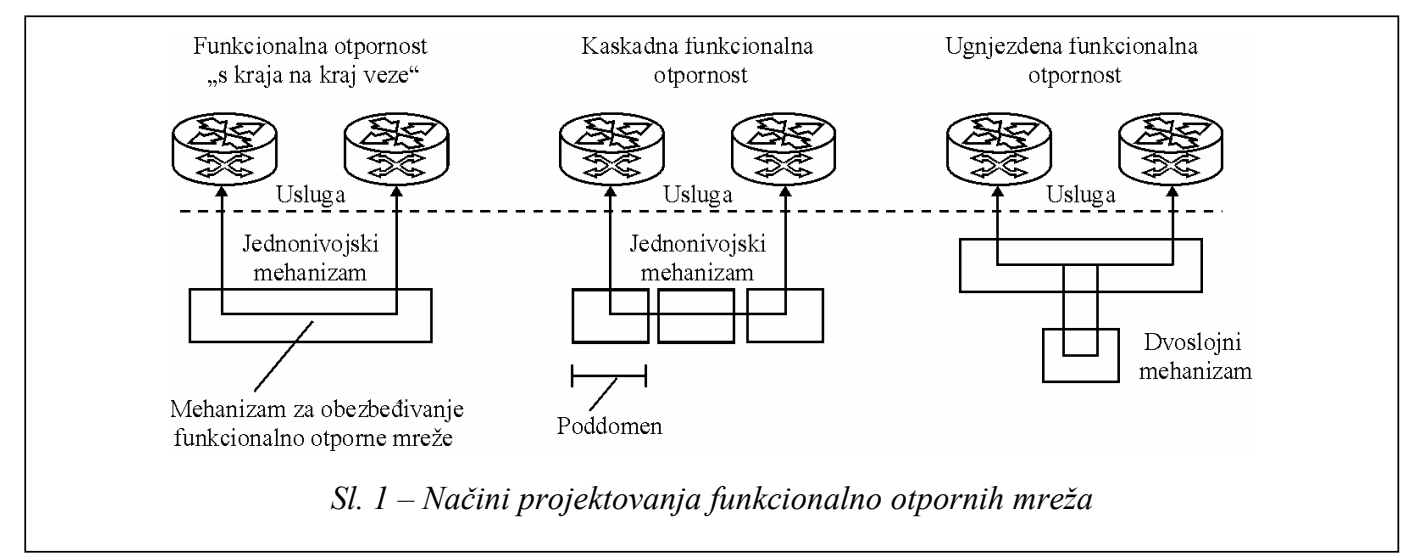


- kaskadna funkcionalna otpornost mreže - postoji više mehanizama koji obezbeđuju ovu otpornost, pri čemu se određeni mehanizmi i procedure primenjuju sekvencijalno, tj. jedna za drugom;

- ugnjezdena funkcionalna otpornost - postoji više mehanizama koji obezbeđuju funkcionalnu otpornost, pri čemu se oni koriste za jedan isti domen.

\section{Tipovi zaštite mreža od otkaza}

Postoji više tipova zaštite računarskih MPLS/GMPLS mreža, koji se mogu koristiti radi obezbeđenja njihove funkcionalne otpornosti. To su:

- zaštita $1+1$ - kod koje se saobraćaj koji se štiti šalje istovremeno preko dve paralelne putanje u mreži, $s$ tim što $u$ toku normalnog rada prijemni entitet prima dva jednaka saobraćajna toka, birajući jedan od njih, ali kada jedna od putanja otkaže, prijemni entitet se prebacuje na prijem saobraćaja sa ispravne putanje;

- zaštita 1:1 - kod koje se, takođe, koriste dve paralelne putanje u mreži, ali $\mathrm{u}$ toku normalnog rada nema saobraćaja preko alternativne putanje, već se u slučaju otkaza na primarnoj putanji predajni i prijemni računar prebacuju na alternativnu putanju;
- zaštita 1:N - koja predstavlja specijalni slučaj zaštite tipa $1: 1$, pri kojoj $\mathrm{N}$ radnih putanja deli jednu pomoćnu zaštitnu putanju, što obezbeđuje funkcionisanje mreže samo ako se pojavi jedan otkaz u domenu mreže koji se štiti.

Izbor određenog tipa zaštite vrši se prilikom projektovanja mreže, na osnovu projektnih zahteva.

\section{Metode oporavka mreže od otkaza}

MPLS protokol obezbeđuje metode opravke računarske mreže nakon otkrivanja otkaza u mreži. MPLS mehanizmi za zaštitu od otkaza koriste pomoćne putanje na koje se saobraćaj preusmerava kada se u mreži ustanovi otkaz.

Analiza načina projektovanja funkcionalne otpornosti i tipova zaštite paketskih računarskih mreža pokazuje da se ova rešenja mogu primenjivati samo kod otklanjanja otkaza u računarskoj MPLS/GMPLS mreži.

Poznata su tri statička modela oporavka (restauracije) mreže:

- Globalni model oporavka (opravke) računarske mreže prikazan je na slici 2 , kod kojeg je ulazni čvor namenjen za ponovno uspostavljanje putanje kroz mrežu kada se pojavi signal indikacije otkaza.

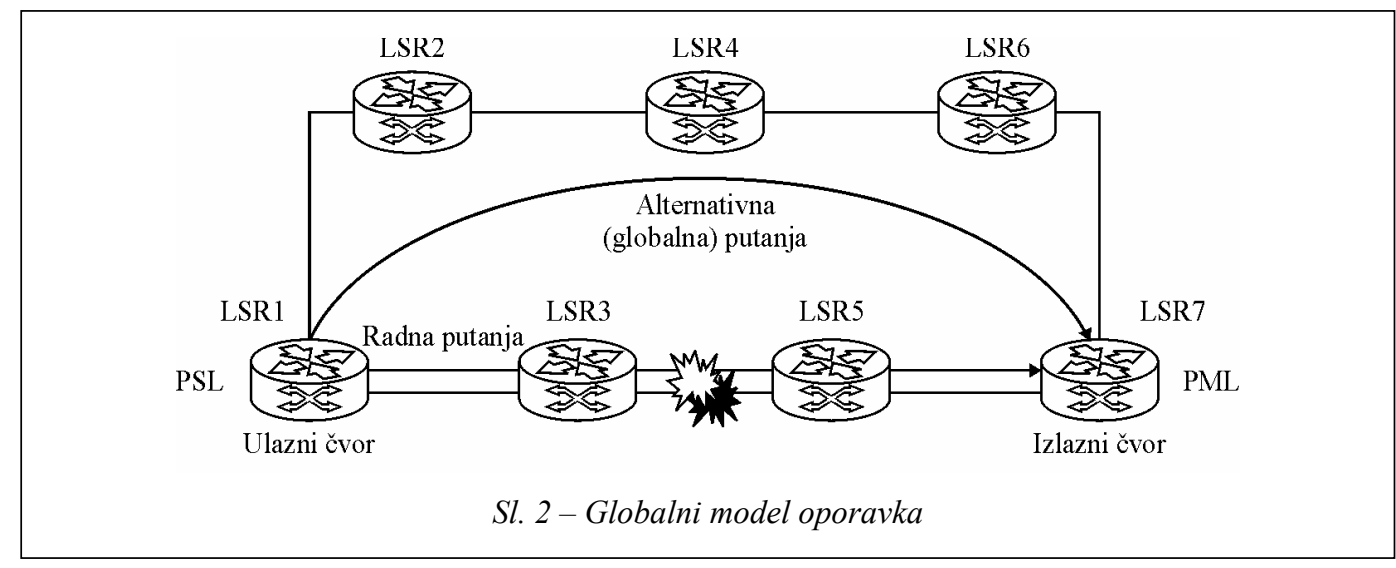


Globalni model zahteva alternativnu putanju za svaku radnu putanju. Globalna zaštita je uvek aktivna na ulaznom čvoru, bez obzira na to gde se otkaz pojavio duž radne putanje.

- Lokalni model oporavka računarske mreže (prikazan je na slici 3), koji služi da zaštiti od otkaza linka ili čvora samo deo radne putanje, bez obzira na to gde se on pojavi duž radne putanje.

- Model povratne zaštite (prikazan je na slici 4), kojim se saobraćaj preusmerava nazad do izvornog čvora (rutera) zaštićene putanje.

U trenutku kada se ustanovi otkaz, ruter na kraju linka u otkazu preusmerava dolazni saobraćaj u suprotnom smeru, odnosno ka ulaznom čvoru. Ovaj model po- godan je u aplikacijama gde su saobraćajni tokovi osetljivi na gubitke informacija. Mana modela povratne zaštite jeste to što su potrebne dve pomoćne putanje da bi se obezbedila zaštita. Drugi nedostatak je kašnjenje, koje nastaje zbog vremena potrebnog da se prenese indikacija o otkazu.

Navedeni tipovi zaštite i modeli oporavka mreže nisu efikasni u zaštiti računarske mreže od destruktivnih dejstava. Oni otklanjaju pojedinačne otkaze, a nisu efikasni u slučaju istovremene destrukcije više linkova i čvorova računarske mreže. Takođe, mora se imati u vidu da se pomenuti modeli mogu primeniti samo kod MPLS/GMPLS mreža, dok za druge tipove računarskih mreža nisu primenljivi.

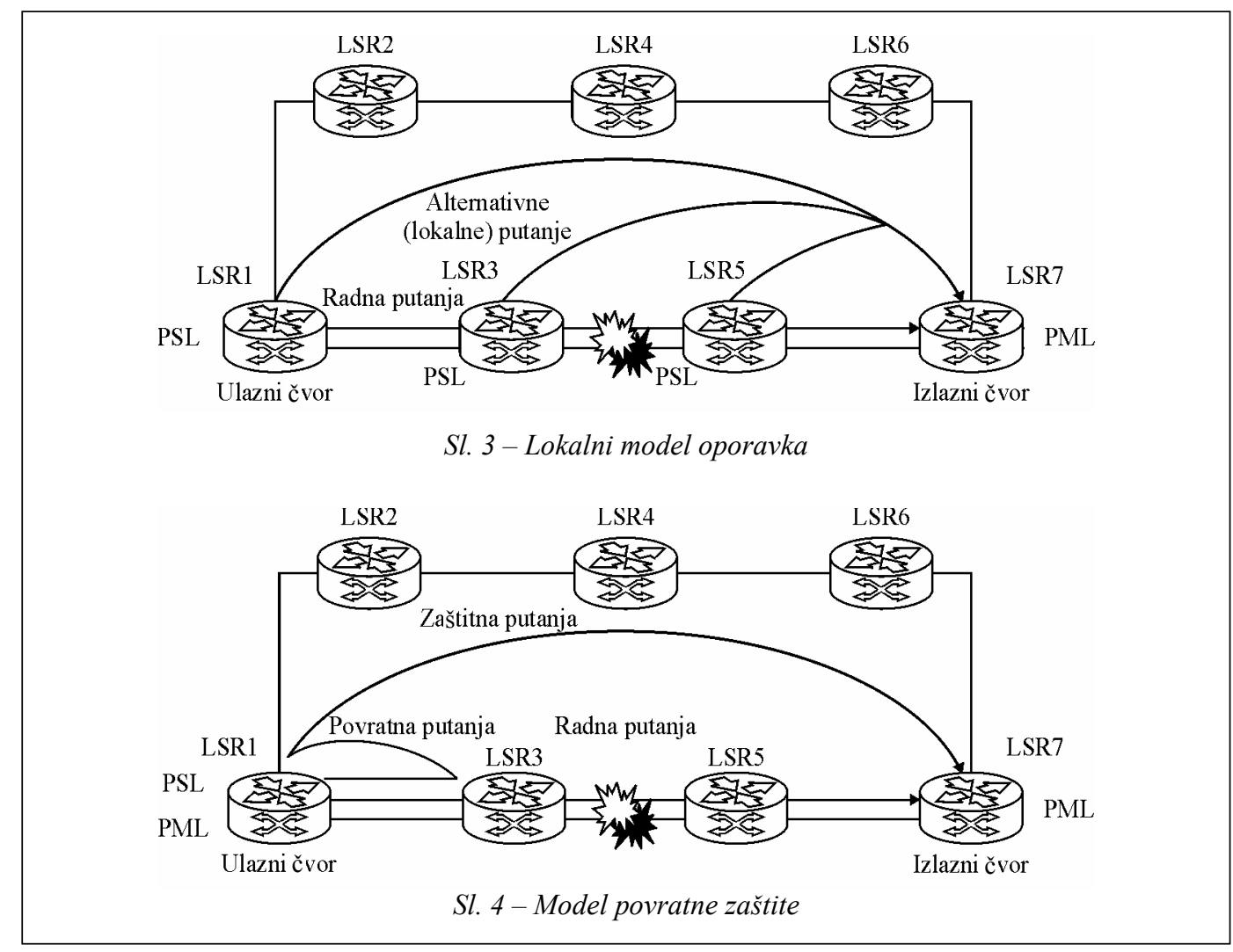


Funkcionalna otpornost računarskih mreža je neophodna da bi data mreža mogla da zadovolji zahteve za osnovne parametre QoS-a. Prema preporukama G.1000 i G.1010, to su: kašnjenje, varijacija kašnjenja i verovatnoća gubitka informacija. Ispunjavanje ovih zahteva preduslov je da računarska mreža omogući komunikaciju podacima u realnom vremenu, kao i multimedijalni saobraćaj. Takođe, računarska mreža treba da zadovolji ove zahteve i u slučaju destruktivnog ugrožavanja.

\section{Koncepcija paralelnog umrežavanja}

Koncepcija paralelnog umrežavanja računara prikazana je na slici 5. Na svaku od mogućih N WAN mreža, računar ili LAN povezuje se korišćenjem samo jednog univerzalnog modema.
WAN mreže, na koje se povezuju računari ili LAN mreže, mogu biti:

- iznajmljeni kanali telefonske analogne ili digitalne mreže;

- ISDN - digitalna mreža integrisanih službi;

- pokretne KT radio-mreže;

- mobilne bežične VVF/UVF radio-mreže;

- frame relay mreže;

- IP ruterske mreže;

- satelitski kanali, odnosno mreže;

- kablovske žične i optičke mreže;

- telefonske radio-relejne mreže itd.

Mrežne performanse navedenih vrsta telekomunikacionih mreža moraju biti u granicama koje su definisane određenim standardima. Prenos podataka u realnom vremenu uspešno se može realizovati samo ako je kvalitet prenosa signala u referentnim granicama [4]. S obzirom na to da se performanse ovih mreža znat-

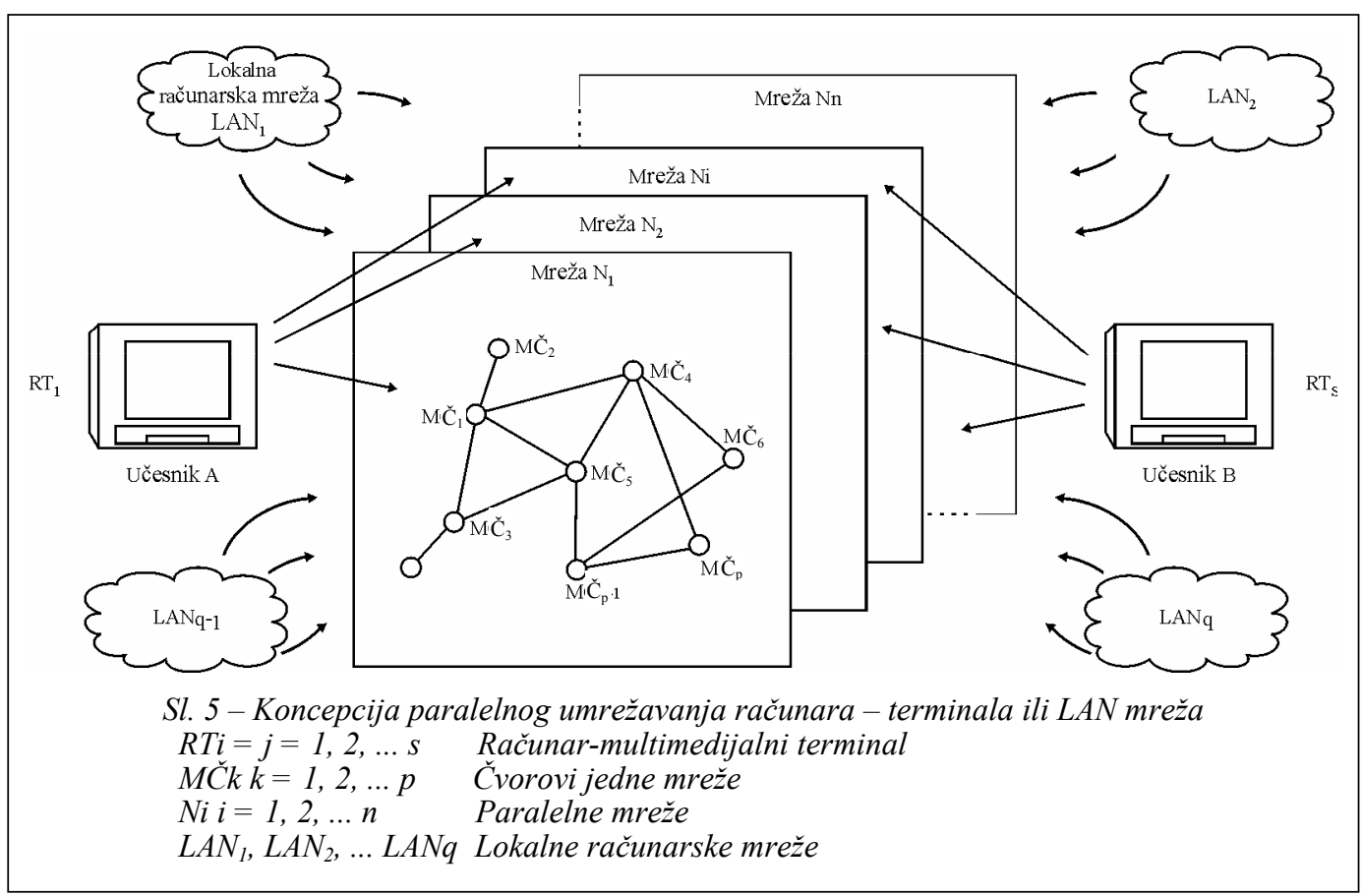


no razlikuju, računari se na svaku od njih moraju povezivati korišćenjem različitih tipova modema, odnosno modulisanih signala. Zbog toga se računari na te mreže povezuju jednim univerzalnim modemom, koji omogućava da se podaci (sa računara) modulišu istovremenim korišćenjem više različitih modulacija. To znači da se podaci (signali) sa računara, različito modulisani u univerzalnom modemu, prenose istovremeno preko kanala pojedinačnih mreža. Prijemni univerzalni modem utvrđuje kvalitet svakog primljenog signala, a ka računaru upućuje demodulisani najkvalitetniji signal. Pod najkvalitetnijim signalom podrazumeva se onaj koji ima minimalno kašnjenje, varijaciju kašnjenja (džiter) i najmanje gubitke informacije. Ukoliko neka od $\mathrm{N}$ transportnih mreža bude onesposobljena destruktivnim dejstvima, ona ne utiče na mogućnost i kvalitet komunikacije podacima u računarskoj mreži.

Praktična provera efikasnosti paralelnog umrežavanja izvedena je $\mathrm{u}$ realnim uslovima kada je jedna namenska računarska mreža bila izložena destruktivnom razaranju. Podaci su prenošeni preko tri paralelne mreže, od kojih je jedna bila pokretna KT radio-mreža. Povezivanje na pomenute mreže ostvareno je korišćenjem multitonskog modema M-2400, koji omogućava otpremanje, odnosno prijem podataka istovremeno sa dve mreže.

Modem M-2400 automatski utvrđuje kvalitet signala, poređenjem džitera faze multitonskih modulisanih signala. Time se omogućava da prema računaru bude prosleđen signal sa najboljim kvalitetom. Sa tri paralelno povezane transportne mreže obezbeđena je zahtevana funkcio- nalna otpornost, uprkos destrukciji osnovne mreže, na koju su se računari uobičajeno povezivali u normalnoj eksploataciji.

\section{Univerzalni modem i povezivanje računara na paralelne mreže}

Paralelno umrežavanje tehnički je izvodljivo pod uslovom da se koristi modem (kojim se povezuje računar ili LAN na WAN mreže) koji generiše dva ili više različito modulisanih signala. Ti modulisani signali sa modemskih interfejsa prenose se preko odgovarajućih transportnih mreža ka drugom modemu, odnosno računaru ili LAN-u.

Univerzalni modem je projektovan [2] tako da omogući komunikaciju - prenos podataka, istovremenim povezivanjem računara preko više nezavisnih telekomunikacionih mreža. Drugim rečima, univerzalni modem u upotrebnom i funkcionalnom smislu predstavlja multimodem. On objedinjava više različitih tipova modema u jednom uređaju, a prilikom komunikacije ti modemi otpremaju ili primaju istu poruku, odnosno podatke. Povezan sa jednim univerzalnim modemom, računar, terminal, senzor (radar) ili LAN priključuje se istovremeno na više WAN mreža.

Univerzalni modem [2] obuhvata funkcije sledećih klasičnih tipova modema:

- FSK V.23 asinhroni modem, čije su funkcije i tehničke karakteristike definisane ITU-T preporukom V.23;

- paralelni multitonski modem, čije su funkcije definisane standardom MILSTD-188C, tačka 4.5.7, koji omogućava prenos podataka brzinom $2400 \mathrm{~b} / \mathrm{s}$ preko KT radio-mreža; 


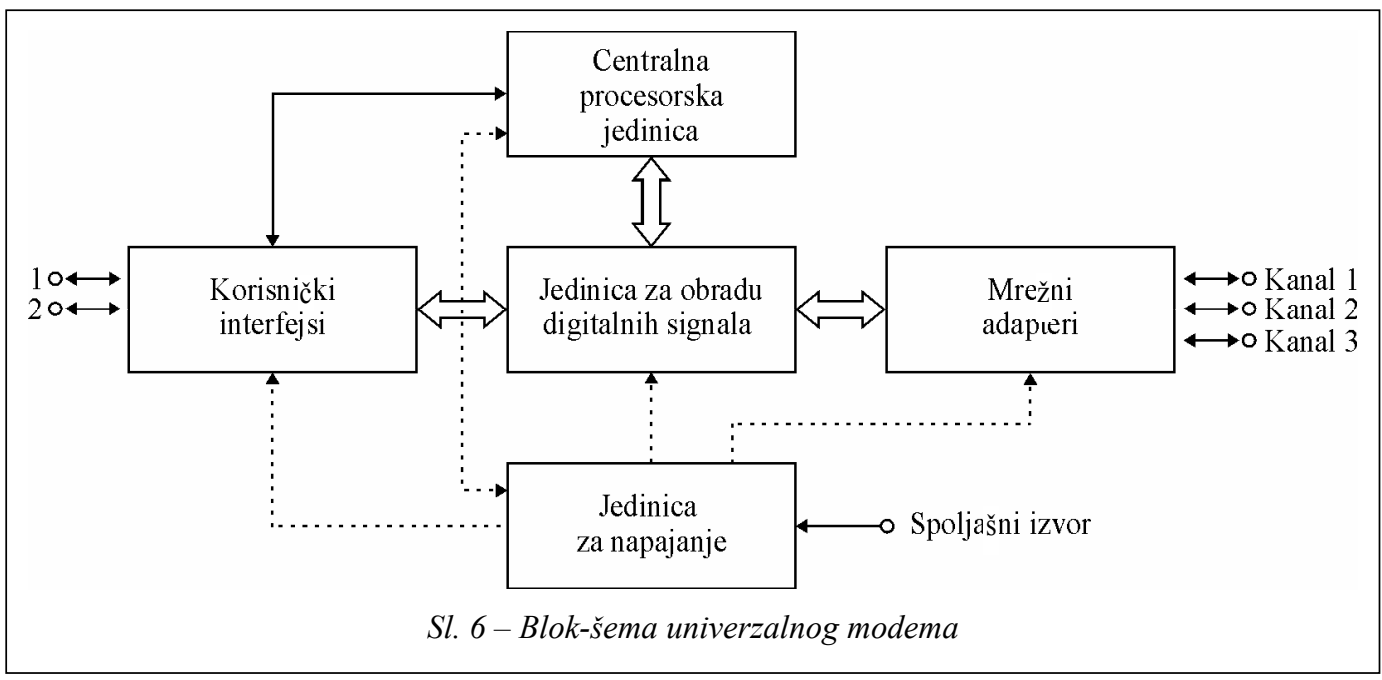

- dupleksni V.22 bis modem, čije su funkcije i karakteristike date u ITU-T preporuci V.22 bis;

- modem V.26, za prenos podataka preko 4-žičnih kanala, čije su tehničke karakteristike definisane UTU-T preporukom V.26;

- dvožični dupleksni modem V.32, čije su performanse date ITU-T preporukom V.32;

- modem 2B1Q, za komunikaciju preko ISDN mreža i prenos podataka u osnovnom opsegu bitskim brzinama do $144 \mathrm{~kb} / \mathrm{s}$, čije su karakteristike definisane ETSI standardima;

- jednotonski modem, za prenos podataka brzinama do $16 \mathrm{~kb} / \mathrm{s}$ preko VVF-
UVF radio-mreža i satelitskih veza, čije su karakteristike definisane standardom MIL-STD-188-181-A;

- modem za prenos podataka prema NATO standardu STANAG 4285.

Blok-šema univerzalnog modema prikazana je na slici 6 .

Osnovni elementi univerzalnog modema su: centralna procesorska jedinica (mikroprocesor), jedinica za obradu digitalnih signala (sa DSP i fleš memorijama), mrežni adapteri (interfejsi prema mrežama), korisnički interfejsi i jedinica za napajanje.

Blok šema jedinice za obradu digitalnih signala prikazana je na slici 7 . U ovoj jedinici softverski se realizuju sledeće funkcije: upravljanje komunikaci-

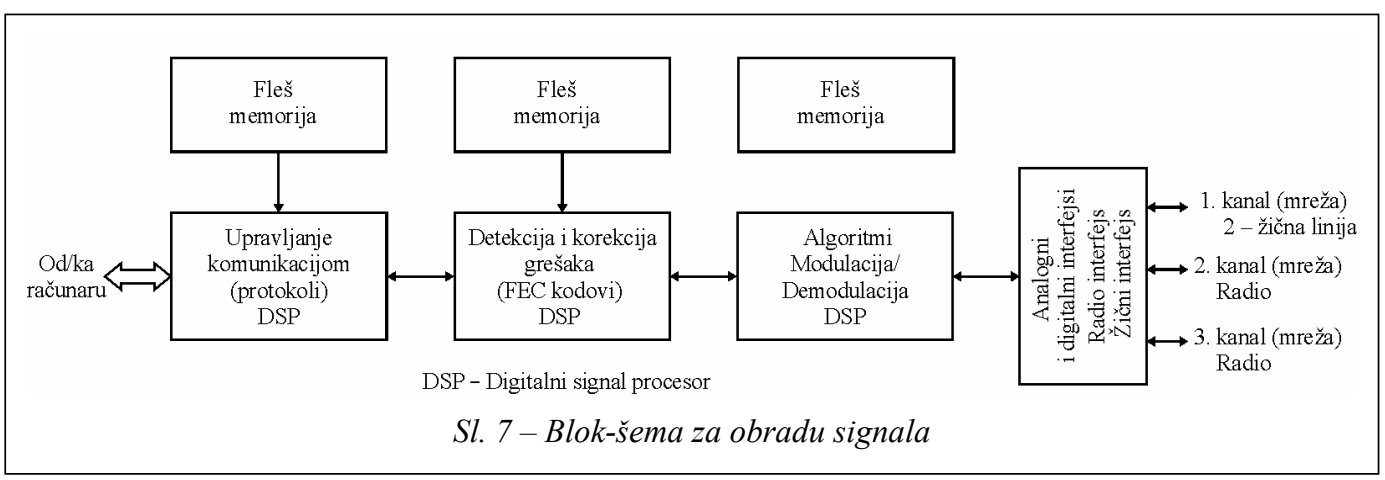


jom (komunikacioni protokoli), kodovanje radi detekcije i korekcije grešaka koje su nastale prilikom prenosa podataka i modulacije - demodulacije signala.

Sve funkcije modema realizovane su softverski. Softverski modulatori i demodulatori, softverska sinhronizacija, kodovanje i dekodovanje i druge softverski realizovane funkcije omogućile su koncentraciju funkcija brojnih klasičnih modema u jednom uređaju. Bez izmena $u$ hardveru, univerzalnom modemu mogu se dodavati funkcije drugih željenih tipova modema. Programi koji obavljaju ove funkcije modema uskladišteni su u fleš memoriji, čime je olakšano i ubrzano biranje odgovarajuće modulacije prema performansama mreže [4] na koju se upućuju modulisani signali.

\section{Zaključak}

Predstavljena koncepcija tehničkog rešenja paralelnog umrežavanja računara i lokalnih pristupnih mreža, zasnovana na korišćenju posebnog univerzalnog modema, omogućava efikasno rešenje zaštite WAN računarskih mreža u slučaju destruktivnih dejstava po komunikacionom sistemu nekog regiona ili neke zemlje. Rezultati praktične primene ovog rešenja, u uslovima kada je komunikacioni sistem vojske jedne zemlje bio izložen destrukciji bombardovanjem, pokazuju da se na ovaj način može ostvariti funkcionalna raspoloživost i efikasnost određene računarske mreže.

Literatura:

[1] Jevtović, M.: Multimedijalne telekomunikacije, ISBN 86903281-6-5, Grafo-Žig, Beograd, 2004.

[2] Jevtović, M.: Projekat realizacije univerzalnog modema, VTI, Beograd, interni dokument, 2002.

[3] Jevtović, M.: Kvalitet usluga telekomunikacionih mreža, ISBN 86-903281-1-4, Grafo-Žig, Beograd, 2002.

[4] Jevtović, M.: Univerzalni modem - Laboratorijska ispitivanja i merenje parametara kanala na linkovima računarskih mreža, Fakultet tehničkih nauka, Katedra za računarsku tehniku i računarske komunikacije, Novi Sad, interni dokument, 2003 